\title{
Tetracycline tooth discolouration in Benin City
}

\author{
Matthew A Sede
}

\begin{abstract}
This retrospective study was conducted to examine the incidence and pattern of tetracycline-related tooth discolouration in patients seen at the restorative dental clinic of the University of Benin Teaching Hospital, Benin City, from 1998 to 2002. During the period, 81 patients consisting of 31 males and 51 females, aged 11-37 years, presented with various degrees of tetracycline tooth discolouration. These patients accounted for $2.2 \%$ of the 3750 patients that were seen during the period under review. In $29.5 \%$ of the patients, hypoplasia was associated with tetracycline discolouration. Of these, $71.4 \%$ were observed in the category with severe discolouration of teeth. A non-genetic pattern of tetracycline tooth discolouration was observed in $40.7 \%$ of the patients, with discolouration in sibling's only accounting for $51.5 \%$ of those affected. There is a need for continuous education of patients and clinicians on the consequences of using tetracycline and its minocycline derivatives in children and pregnant women.
\end{abstract}

\section{INTRODUCTION}

Discolouration of teeth is an aesthetic problem that is linked to a variety of causes. The role of tetracycline in tooth discolouration is well documented. ${ }^{1}$ Tetracycline tooth discolouration is of tremendous aesthetic concern to patients. $^{2}$ Like most permanent tooth stain, it is a source of embarrassment, leading to a reduced self-esteem. ${ }^{3}$ These discolorations are the consequence of tetracycline treatment for childhood infection, or when administered to pregnant women after $14-16$ weeks of gestation. ${ }^{4}$ Tooth discolouration manifests in $50 \%$ of infants

KEY WoRDS: Tooth discoloration, tetracycline, incidence, Benin City

Correspondence: Dr M. A. Sede, P. O. Box 4641, Benin City, Edo State, Nigeria. E-mail: sede_matt@yahoo.co.uk exposed to tetracycline in utero. ${ }^{5}$ Sometimes in addition to the discolouration of teeth, there is an associated enamel hypoplasia.

The occurrence of tetracycline tooth discolouration is not limited to children. It is known to affect adult dentition following prolonged administration of tetracycline or its minocycline derivative. ${ }^{1}$ However, studies have suggested that a concomitant use of vitamin $\mathrm{C}$ or other antioxidants may help prevent adult onset of tooth discolouration caused by minocycline. ${ }^{1}$

Tetracycline discolouration is classified as an intrinsic discolouration of dentine. ${ }^{7}$ The staining pattern ranges from light yellow to a localised dark grey, purple, blue or brown colour, ${ }^{8}$ which are a manifestation of the various forms of tetracycline administered. ${ }^{2}$ The severity of staining is graded as mild, moderate and severe. The severe type is 
characterised by dark grey, purple or blue discolouration, in conjunction with cervical banding. ${ }^{9}$ The unique staining of teeth by tetracycline notwithstanding, bright yellow fluorescence is diagnostic when tetracycline stained teeth are viewed under ultraviolet light.

The purpose of this study was to determine the incidence of tetracycline-related tooth discolouration, treatment offered and patients' perception of treatment outcome.

\section{PATIENTS AND METHODS}

All the case records of patients who presented at the restorative dental clinic of the hospital with tetracycline tooth discolouration between January 1998 and December 2002 were retrieved from the medical records unit of the dental clinic and analysed. Information was obtained on demographic parameters, family history of tetracycline tooth discolouration, pattern of discolouration, treatment given and treatment outcome.

Criteria for assessing the severity of tooth discolouration as gleaned from the case notes appeared to be based on the description by Jordan et al, ${ }^{9}$ who graded the severity of staining as slight, moderate or severe. The slight staining was recorded as a light yellow or light grey uniform discolouration of the entire dentition without banding or concentration of stain in any part of the crown. A darker uniform yellow or grey staining without banding was recorded as moderate staining.
The dark grey, purple or blue discolouration, with cervical banding, was recorded as severe.

\section{RESULTS}

During the five-year period of this study, a total of 3750 new patients visited the restorative dental clinic, with 81 (2.2\%) having tetracycline discoloured teeth. There were 31 (38.3\%) males and 50 (61.7\%) females, with a male to female ratio of $1: 1.6$. Their age range was 11 to 37 years with a mean age of 21.1 years (Table 1 ).

Medical records showed that all the patients had their teeth stained since childhood, but there were no details on who (mother or child) took the tetracycline antibiotic, time of administration and the condition for which it was administered. Similarly, information on the source of drug prescription was inadequate; only 25 (30.9\%) patients confirmed selfmedication by mothers.

Table 2 shows gender classification of tooth staining and defects in the patients. The occurrence of hypoplasia in association with tetracycline discolouration was observed in 21 (25.9\%) patients. Of the patients with hypoplastic teeth, $71.4 \%$ were observed in the category with severe discolouration. Thirty two (39.5\%) patients presented with the severe tetracycline discolouration, as against 25 (30.9\%) and 24 (29.6\%) with mild and moderate discolorations respectively.

\section{Table 1 Age and gender distribution of patients}

\begin{tabular}{llcr}
\hline Age range & $\begin{array}{l}\text { Male } \\
\mathbf{n}(\%)\end{array}$ & $\begin{array}{c}\text { Female } \\
\mathbf{n}(\%)\end{array}$ & $\begin{array}{c}\text { Total } \\
\mathbf{n}(\%)\end{array}$ \\
\hline $11-15$ & $9(11.1)$ & $6(7.4)$ & $15(18.5)$ \\
$16-20$ & $7(8.6)$ & $14(17.3)$ & $21(25.9)$ \\
$21-25$ & $9(11.1)$ & $17(20.9)$ & $26(32.0)$ \\
$26-30$ & $3(3.7)$ & $8(9.9)$ & $11(13.6)$ \\
$31-35$ & $2(2.5)$ & $3(3.7)$ & $5(6.2)$ \\
$>35$ & $1(1.2)$ & $2(2.5)$ & $3(3.7)$ \\
\hline Total & $31(38.3)$ & $50(61.7)$ & $81(100.0)$ \\
\hline
\end{tabular}


Table 2 Gender classification of staining and defect

\begin{tabular}{lccc}
\hline Staining & $\begin{array}{c}\text { Male } \\
\mathbf{n}(\mathbf{\%})\end{array}$ & $\begin{array}{c}\text { Female } \\
\mathbf{n}(\mathbf{\%})\end{array}$ & $\begin{array}{c}\text { Total } \\
\mathbf{n}(\mathbf{\%})\end{array}$ \\
\hline $\begin{array}{l}\text { Mild } \\
\text { With hypoplasia }\end{array}$ & - & - & - \\
$\quad$ Without hypoplasia & $9(11.1)$ & $16(19.8)$ & $25(30.9)$ \\
$\begin{array}{l}\text { Moderate } \\
\text { With hypoplasia }\end{array}$ & $2(2.5)$ & $4(4.9)$ & $6(7.4)$ \\
$\quad$ Without hypoplasia & $5(6.2)$ & $13(16.0)$ & $18(22.2)$ \\
$\begin{array}{l}\text { Severe } \\
\quad \text { With hypolasia }\end{array}$ & & $7(8.6)$ & $15(18.5)$ \\
$\quad$ Without hypoplasia & $8(9.9)$ & $11(13.6)$ & $17(21.0)$ \\
\hline
\end{tabular}

Table 3 Family history of tooth discoloration

\begin{tabular}{lc}
\hline Family member affected & Number of patients (\%) \\
\hline Not stated & $9(11.1)$ \\
Nil & $39(48.1)$ \\
Siblings & $17(21.0)$ \\
Sibling and mother & $7(8.6)$ \\
Mother only & $8(9.9)$ \\
Father & $1(1.2)$ \\
\hline
\end{tabular}

Table 3 shows the family history of tooth discolouration. In 9 (11.1\%) patients the family status was not indicated. Most patients (48.1\%) had no family history of discolouration, but in 17 (20.9\%) patients there was discolouration in siblings. Discolouration in sibling and mother, mother only, and father only accounted for 7 (8.6\%), 8 (9.9\%) and 1 (1.2\%) patient respectively.

Table 4 shows the various treatments received by the patients. Twenty seven (33.3\%) patients did not receive any form of treatment. Majority (37.0\%) of patients had direct labial composite facing, while 19 (23.4\%) received jacket crowns. Only 5 (6.1\%) had vital tooth bleaching using 35\% carbamide peroxide gel.
Table 4 Various types of treatment received

\begin{tabular}{lc}
\hline Treatment & Number of patients (\%) \\
\hline Nil & $27(33.3)$ \\
Direct labial & \\
composite & $30(37.0)$ \\
Jacket crowns & $19(23.5)$ \\
Bleaching & $5(6.2)$ \\
\hline
\end{tabular}

Figure 1 shows patients' perception of their treatment outcome. Thirty six (66.7\%) patients expressed satisfaction with treatment received, while $13(24.0 \%)$ patients who had direct labial composite facing were dissatisfied with the outcome of their treatment. The opinion of 5 (9.3\%) patients was not recorded. 
Figure 1 How patients perceived treatment outcome

\section{DISCUSSION}

During the period of study, $2.2 \%$ of the study population had tetracycline tooth discolouration. There was however no known local studies for comparison, but a Norwegian study $^{10}$ revealed $0.4 \%$ incidence in a population of 3,157 children. Similarly, during the period 1979 to 1995 a Dutch centre for monitoring of adverse reaction to drugs reported only seven cases of tetracycline tooth discolouration. ${ }^{11}$ In a separate study of 910 children in Madrid ${ }^{12}$ a prevalence rate of $3.1 \%$ was observed.

The degree and intensity of tooth discolouration varied amongst the patients from mild to severe discolouration. In addition, there was associated enamel hypoplasia in some moderate and severely discoloured teeth. A previous report ${ }^{13}$ cited the occurrence of hypoplasia with tetracycline discolouration in a 15-year-old female Nigerian patient.

In this study prenatal or childhood administration of tetracycline antibiotic was the established cause of discolouration. There was no case of adult onset of tooth discolouration, but Chiappinelli et $\mathrm{al}^{4}$ reported a case of adult discolouration resulting from prolonged administration of tetracycline. This study reveals the existence of a family history of tetracycline discolouration amongst some of the patients studied, a trend that may be linked to the prevalence of childhood illnesses and a high incidence of self-medication amongst the local populace. This pattern of family history may indicate the level of ignorance about tooth discolouration as a possible side effect of tetracycline usage in pregnancy and early childhood.

The treatment of tetracycline discolouration poses a difficult challenge to the dentist ${ }^{2}$ because of the varied intensity of tooth staining, requiring a more natural appearance. The mild and moderate tetracycline discolorations are uniformly dispersed throughout the crown, varying from light to moderate yellow or grey colouration, which frequently responds to vital bleaching. ${ }^{7}$ In this study, direct composite facing was mostly used for the mild and moderate discolorations. In the past, the modified internal bleaching technique ${ }^{14}$ was adopted for severe tetracycline discolorations, but the need for elective endodontic treatment made it unattractive. 
Generally, bleaching alone is inadequate in the treatment of severe discolorations. The most realistic treatment options include composite, ceramic veneer or crowning of the affected teeth. $^{7}$

The treatment pattern in this study showed that the patients received labial composite facing, jacket crowns (acrylic and porcelain) and vital bleaching for the various categories of discolorations. Only $9.3 \%$ of patients treated had vital tooth bleaching even though $58 \%$ of the patients were indicated for vital bleaching. This low utilisation of tooth bleaching procedures in the management of tetracycline staining could be attributed to the long-standing belief that tetracycline discoloured teeth are not indicated for vital bleaching. ${ }^{15}$ On the other hand, low income levels may have limited the desire of the patients for tooth bleaching procedures. On the contrary, the high demand for composite may be due to its relatively lower cost than equivalent anterior ceramic restorations. ${ }^{16}$

In the past, most dentists and patients seemed to have preference for jacket crowns as the treatment for severe intrinsic tooth discolouration. ${ }^{3}$ This preference was not observed in this study, where only $35.2 \%$ of the patients had jacket crowns. The irreversible damage to tooth substance in an attempt to provide sufficient bulk for a jacket crown ${ }^{17}$ has given way to more conservative treatment like macro-abrasion, vital tooth bleaching and ceramic laminate veneers. In the treatment of severe tetracycline tooth discolouration, Strasser ${ }^{18}$ favours ceramic laminate veneers for their probable colour stability, durability and longevity.

The perception of treatment outcome by patients was mostly positive except in $43.3 \%$ of those who had direct composite facing. Their disappointment may be due to the failure of the dentist to achieve the desired natural look of dentition after restoration. Better aesthetic results are made possible in severely discoloured teeth by adequate tooth reduction to accommodate a masking agent over which a composite of sufficient thickness is placed. ${ }^{19}$

In conclusion, this study shows the presence of a non-genetic pattern of tetracycline tooth discolouration amongst patients. This non-genetic pattern of discolouration is probably a consequence of the poor knowledge of the unsightly side effect of tetracycline and its minocycline derivatives amongst the populace. In order to avoid the emotional and financial problems associated with tetracycline discolouration of teeth, there is a need to check the indiscriminate use of the antibiotic through an aggressive enlightenment campaign directed at the patients and clinicians.

\section{ACKNOWLEDGEMENT}

I am grateful to the staff of the Medical Records Department of the Dental Clinic for their excellent cooperation during the retrieval of records for this study.

\section{References}

1. Cheek CC and Heymann HO. Dental and oral discolorations associated with minocycline and other tetracycline analogs. $J$ Esthet Dent 1999; 11(1): 43-48.

2. Fieldler RS and Reichl RB. Combined professional and home care night guard bleaching of tetracycline stained teeth. Gen Dent 2000; 48(3): 257-261.

3. Okuda WH. Using a modified subopaquing technique to treat highly discoloured dentition. J Am Dent Assoc 2000; 131(7): 945950.

4. Chiappinelli JA and Walton RE. Tooth discoloration resulting from long-term tetracycline therapy. A case report. Quint Int 1992; 23(8): 539-541.

5. Haas DA, Pynn BR and Sands TD. Drugs use for pregnant or lactating patients. Gen Dent 2000; 48(1): 54-60.

6. Mckenna BE, Lamey PJ, Kennedy JG and Bateson J. Minocycline induced staining of adult permanent dentition: a review of the literature and report of a case. Dent Update 
1999; 26(4): 160-162.

7. Nixon RL and Margeas RL. The great cover up - tetracycline stain revisited - 1 : case study. Contemp Esthet 2001; 5(4): 16-26.

8. Bevelander $G$ and Nakahara $H$. The effect of diverse amount of tetracycline on fluorescence and coloration of teeth. J Padiatr 1996; 68(1): 114-120.

9. Jordan RE, Suzuki $M$ and Croll TP. Conservative Treatment of the Discoloured Dentition. Esthetic Composite Bonding Techniques and Materials. 2nd edition. Chicago: Mosby Year Book Inc., 1993, pp 104-105.

10. Ulvestad H, Lokken $\mathrm{P}$ and Mjorud F. Discoloration of permanent front teeth in 3,157 Norwegian children due to tetracycline and other factors. Scand J Dent Res 1978; 6(3): 147-152.

11. de Wit ME, Stricker BH and Porsius AJ. Discoloration of teeth by drugs. Ned Tijdschr Tandheelkd 1996; 103(1): 3-5.

12. Dominguez RV, Acedo Diaz-pache MV, Gil $\mathrm{MA}$, et al. Prevalence of tooth discoloration from tetracycline in a school population. Av Odontoestomatol 1998; 5(8): 541-546.
13. Ogunyinka A. Enamel staining and hypoplasia due to multiple causes in a Nigerian adolesence: report of a case. Afr $J$ Med Med Sci 1998; 27(3-4): 247-250.

14. Aldecoa EA and Mayordomo FG. Modified internal bleaching of severe tetracycline discoloration: a 6-year clinical evaluation. Quint Int 1992; 23: 83-89.

15. Weinberg SP. Bleaching tetracycline stained teeth: a combined approach. Dent Today 1997; 8:56-59.

16. Dietschi D. Layering concept in anterior composite restorations. J Adhesive Dent 2001; 3: 71-80.

17. Tudts M, Van-Meerbeek B, Lambrechts $P$ and Vanherle G. Micro-abrasion of enamel: an alternative to the elimination of superficial demineralisation and decalcification. Rev Belge Med Dent 1996; 51(3): 54-71.

18. Strassler HE. Esthetic restoration of discoloured teeth using porcelain laminate veneers. Compend Cont Educ Dent 1998; 19(5): 518-525.

19. Roeters JJ. Extended indication for directly bonded composite restoration: a clinician's view. J Adhesive Dent 2001; 3: 81-87. 